\title{
Eficacia de los mecanismos de protección de derechos de las comunidades indígenas víctimas de desplazamiento forzado en Colombia
}

Un aspecto recurrente, en las narrativas de la administración actual, se concentra en la reparación a las víctimas como elemento primordial de los procesos políticos de paz. De acuerdo con las versiones públicas, el reconocimiento y la reparación se han constituido en directrices que orientan el quehacer de los funcionarios públicos en distintas instancias administrativas. De la misma manera, las narrativas de reparación y restitución, se han convertido en elementos que, en el ámbito público, han permitido que diversos actores políticos introduzcan retóricas de postconflicto y diálogos de paz (Mora-Gamez, 2013, 11-12).

Sin embargo, estas mismas narrativas de postconflicto, también movilizan el supuesto de que el reconocimiento de las víctimas es una de las acciones estatales requeridas para la construcción de la paz en nuestro país. De hecho, en una entrevista reciente, la Directora de la Unidad de Reparación y Atención Integral a las Víctimas (UARIV) señaló que:

La Ley de víctimas, para nosotros y para el presidente, es como el primer paso para lo que estamos avanzando hoy con los diálogos en la Habana. Es una ley que fortalece los mecanismos democráticos y busca fortalecer la presencia del Estado en lo territorial. Hoy las víctimas existen para el país. ("Hoy las víctimas existen para el país: Paula Gaviria”, 2013, septiembre)

Ante estas afirmaciones, que ejemplifican la agenda estatal vigente, vale la pena preguntarse: ¿qué tan efectivos son los mecanismos de protección de derechos de las comunidades indígenas víctimas de desplazamiento forzado? (tanto los mecanismos judiciales como los administrativos); dado que las dificultades evidenciadas a lo largo de la investigación, van desde el desconocimiento, por parte de los afectados, de cómo funcionan y para qué sirven, hasta los complejos procesos administrativos instituidos por la entidad, pasando por la falta de defensa de la UARIV en los procesos 
judiciales, y la ineficaz y lenta respuesta de las entidades en el transcurso de los procesos administrativos.

\section{Dificultades técnicas y humanas para la inclusión de las vícti- mas en los programas de atención y reparación para las vícti- mas de desplazamiento forzado}

En el ámbito legislativo la Ley 1448 de 2011 (artículo 3), establece que las víctimas de desplazamiento forzado deben inscribirse en el Registro Único de Víctimas (RUV), dado que este es el medio exclusivo a través del cual las personas afectadas por el conflicto armado pueden acceder a los beneficios provistos por el Estado. Sin embargo, aún resulta enigmática la manera como estas directrices configuran diferentes prácticas y experiencias, incorporadas por funcionarios de la UARIV y los reclamantes.

En ciudades como Bogotá, por ejemplo, para ser inscrito en el RUV, es necesario estar desde las primeras horas del día, hacer filas extensas y obtener una ficha o turno para ser atendido (Mora- Gamez, 2013, pág.13). A lo anterior, debe añadirse que no basta con hacer la fila y declarar el hecho por el cual se originó el desplazamiento: el interesado debe esperar 90 días hábiles para que la $U A R I V$, le responda si ha sido o no incluido en el RUV. Si la respuesta fuera negativa, el demandante deberá solicitar que la entidad revise nuevamente su caso y, si fuese en contra la respuesta de la UARIV, podría interponer el recurso de reposición (Ley 1448, 2011, art. 61), es decir, que al término normal de 90 días se le adicionarían 45 días más, sin problema alguno. Ahora bien, esto se entiende, si se suma el término que el interesado tiene para solicitar la revisión de su caso (que son 10 días), más los 15 días con los que cuenta la UARIV para responderle, más el término para reponer la decisión (que son 5 días) más los 15 días que tiene la entidad para resolver el recurso.

Si se logra cumplir con la maratónica tarea de obtener un turno o ficha de atención, es necesario contar con los datos, fechas, hechos y documentos necesarios para llenar el Formato Único de Declaración (FUD), en el cual los funcionarios consignan la información de las personas reclamantes (víctimas). El FUD, como se dijo, contiene distintas codificaciones para la información demográfica y de los hechos victimizantes que orientan al funcionario para que pueda transformar la narrativa en hechos, números, códigos, anotaciones e interpretaciones que, en últimas, reflejarán a la persona que declara -por lo cual la orientación se traduce en presuntas-, instrucciones y soportes sugeridos. De este modo, en los instructivos, con respecto a cada pregunta se solicita insistentemente que se precisen fechas, lugares, registros, nombres, ayudas recibidas y documentos de forma precisa; por ejemplo, según el tipo de hecho victimizante se le otorga un código dentro del sistema, tal como se indica a continuación:

1. Actos terroristas/Atentados/Combates/ Enfrentamientos/ Hostigamientos

2. Amenaza 
3. Delitos contra la libertad e integridad sexual en desarrollo del conflicto armado

4. Desaparición forzada

5. Desplazamiento forzado

6. Homicidio/ Masacre

7. Minas antipersonales/ Munición sin explotar/ Artefacto explosivo improvisado

8. Secuestro

9. Tortura

10. Vinculación de niños, niñas y adolescentes en actividades relacionadas con grupos armados

11. Abandono o despojo forzado de tierras

12. Otro

13. No es víctima ${ }^{5}$

Aunque los discursos de la administración pública, sugieran que este inventario de situaciones busca humanizar y dignificar a las víctimas, el diseño indica que en lugar de promover una aproximación -relativamente empática por parte de los funcionarios hacia las historias de los reclamantes-, el FUD parece alentar prácticas e interacciones de comprobación de la verdad en las declaraciones, o al menos producir esa verdad de forma documental.

Ahora bien, estar inscrito en el RUV no garantiza que la persona reciba pronta y cumplidamente los componentes de atención humanitaria y de reparación administrativa que consagra la Ley 1448 de 2011. Esta ley establece que la atención humanitaria de emergencia debe entregársele a la persona tan pronto haga su declaración de víctima; no obstante, también se debe esperar a que el declarante sea declarado víctima y, por ende, que sea inscrito en el correspondiente registro, es decir, que en el mejor de los casos este tipo de ayuda se entregaría dentro de los 90 días siguientes a la declaración.

Por su parte, la atención humanitaria de transición debe asignarse cada tres meses por núcleo familiar y su monto depende del número de miembros. Así mismo, este tipo de atención se divide en dos componentes: alimentación y alojamiento (la primera a cargo del ICBF y la segunda de la UARIV). A partir de los testimonios de las personas que asistieron a los talleres de formación, realizados a través de la Universidad Santo Tomás, Sede Villavicencio, dirigidos a los miembros de las comunidades indígenas víctimas de desplazamiento forzado asentadas en la misma ciudad, pudo comprobarse que estos plazos no son cumplidos, que la atención humanitaria de transición es entregada cada año (aproximadamente) y que para ser beneficiario de la misma, la entidad ha implementado un complejo sistema de turnos que puntualmente hacen más complicado el procedimiento, lo cual ha generado que las 
víctimas realicen ante la entidad, innumerables peticiones escritas, para que les sea entregada la atención humanitaria. Esta situación, sin embargo, la hemos analizado más detenidamente en el siguiente numeral.

Aunado a lo anterior, se encuentra que la $U A R I V$ no tiene una base de datos organizada y coherente que permita establecer con claridad el número de víctimas registradas, el género, los datos de identificación completos y los hechos victimizantes; y por el contrario, lo que existe es un desorden estructural que hace que el funcionamiento de la entidad se desarrolle de forma caótica y sin mayor planificación. Aunque, formalmente, se establezca una posición distinta. De este modo, se evidenció en el Informe de evaluación de indemnización administrativa y de participación de las víctimas de la violencia en Colombia, presentado por la Contraloría General de la República a la Corte Constitucional, el 03 de mayo de 2013, dentro del proceso de seguimiento para el cumplimiento de la sentencia de tutela T-025 de 2004, que:

El RUV cuenta con 6.861.112 registros (fila de la base de datos) correspondientes a hechos victimizantes denunciados pero, dado que una persona puedo sufrir más de un delito, dicho número no corresponde exactamente al de personas inscritas. El conteo de nombres únicos y otras depuraciones dan como resultado 4.704 .431 personas distintas que detentan la condición de víctimas directas e indirectas (familiares de las primeras) registradas ante el Estado. (...). Debemos subrayar que 833.329 personas (el $18 \%$ del total) no poseen, no informan, no saben o no recuerdan su número de identificación, situación atípica que no puede perderse de vista cuando de distribuir recursos públicos de trata.

\section{Auditoria de Calidad del RUV}

En el anterior informe, la Contraloría General de la Nación concluyó que el RUV presenta las siguientes inconsistencias:

Luego del anterior acercamiento estadístico al fenómeno de la victimización en Colombia usando el RUV temporal a enero 15/2013, CGR examinó la integridad y consistencia de sus datos. A continuación resumimos los principales hallazgos:

No se observó una variable que identifique la fecha del hecho victimizante, lo que impide el análisis a través del tiempo.

Se observaron 4.174 personas mayores de 95 años identificados aún hoy con registro civil de nacimiento; 9 personas con tipo de documentos, bajo la seña de "No aplica”, pero que poseen un número de documento de identidad; 503 personas, que superan la edad de 95 años, presentan tarjeta de identidad propia de menores de edad.

Aparecen 228.084 personas, con datos de nacimiento que no corresponden a ningún formato de fecha, lo que impide calcular su edad. 
Se identificaron 4938 personas, con fechas de nacimiento superiores a la actual, es decir, con edades negativas.

Se hallaron 5889 personas, con nombres de una o dos letras o nombres completos atípicos; lo cual, naturalmente, genera incertidumbre sobre sus identidades (...).

Se detectaron 2.787 cédulas de ciudadanía, con dígitos irregulares.

Se presentaron 15.022 personas, cuyas tarjetas de identidad poseen entre uno y veintiuno dígitos, lo que es irregular en este tipo de documentos.

En el campo denominado número de documento, se observaron 5.218.115 registros únicos (76\% del total), es decir, cerca del $24 \%$ de los registros son repeticiones que crean incertidumbre sobre la identidad de las personas...

\section{Desconocimiento de los mecanismos jurídicos y administra- tivos de protección de derechos por parte de las comunidades indígenas víctimas de desplazamiento forzado}

Otro de los aspectos identificados, que hacen ineficaces los mecanismos de protección de derechos para las comunidades indígenas víctimas de desplazamiento forzado, es el desconocimiento, por parte de las víctimas, de cuáles son estos mecanismos, cómo ejercerlos, ante quién presentarlos, y qué entidades públicas y privadas pueden ayudarles en este proceso. A la anterior conclusión se llegó luego de que, en el desarrollo de esta investigación, la Universidad Santo Tomas, Sede Villavicencio, realizara una serie de talleres pedagógicos para enseñarles a los integrantes de las comunidades indígenas Inga y Tukano de Villavicencio, algunos aspectos generales para que ejercieran de forma directa la protección de sus derechos.

En los talleres pedagógicos sobre "Mecanismos de protección de derechos de las Comunidades Indígenas Inga y Tukano asentadas en la ciudad de Villavicencio, víctimas de desplazamiento forzado" -realizados el 26 de julio y el 2 de agosto de 2014- la investigadora de este proyecto, junto con la conferencista contrata por la Universidad Santo Tomás, Sede Villavicencio, tuvieron la oportunidad de conversar con los asistentes a los talleres (25 integrantes de comunidades indígenas víctimas de desplazamiento forzado asentadas en la ciudad de Villavicencio) y a partir de ello percibir que el $70 \%$ de sus integrantes desconocía totalmente la existencia de tales mecanismos de protección de derechos y cómo el 30 \% restante se ha visto forzado a ejercer alguna acción judicial o administrativa, para reclamar sus derechos. Entre quienes han ejercido los mecanismos legales para la protección de sus derechos, el $60 \%$ se ha limitado a presentar derechos de petición ante las autoridades, y el $40 \%$ ha emprendido acciones de tutela, bien sea para recibir una respuesta de fondo sobre sus peticiones o para reclamar derechos concernientes a sus comunidades como el reconocimiento de territorios, albergues temporales o el otorgamiento de personerías jurídicas para sus cabildos. Las figuras 1 y 2 presentan gráficamente estos datos: 
Figura 1. Porcentaje de asistentes que saben cuáles son los mecanismos de protección de sus derechos como víctimas de desplazamiento forzado.



Figura 2. Porcentajes de acciones judiciales o administrativas que se han ejercido para proteger los derechos de las comunidades indígenas Inga y Tukano, víctimas de desplazamiento forzado asentadas en la ciudad de Villavicencio.

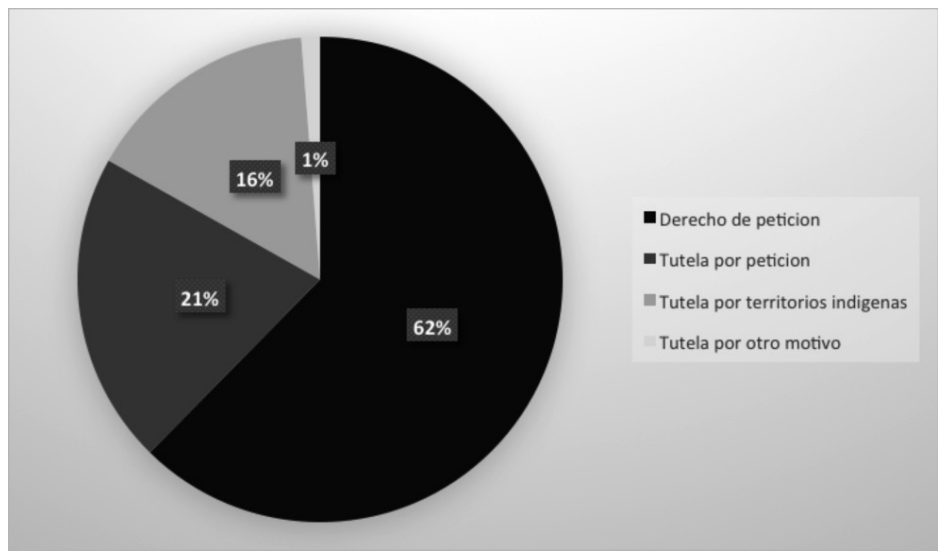

De acuerdo con los análisis del material utilizado para sustraer la información graficada con anterioridad, pudo establecerse que los integrantes de las comunidades indígenas, Inga y Tukano, víctimas de desplazamiento forzado asentadas en la ciudad de Villavicencio, identificaron varias circunstancias directamente relacionadas con el objetivo de este estudio. Así, dentro de los hallazgos que pueden servir para identificar por qué esta población desconoce y, por ende, no ejerce los mecanismos jurídicos para la protección de sus derechos, se encontraron estas recurrencias: a) el grado de escolaridad de estas familias; b) la falta de capacitación por parte de las instituciones del Estado y de diversas $O N G$ u organismos internacionales; y c) la desorientación 
de estas personas por la mala información de las instituciones estatales sobre los trámites a seguir.

Además, la satisfacción en cuanto a la capacitación de estas comunidades, ante las instituciones del Estado, es regular en materias como derechos humanos, acciones constitucionales y medios para obtener la reparación integral. Los asistentes, expresaron que hay capacitaciones en otros temas (emprendimiento, cuidado personal, etc.); pero no en derechos humanos. Por otro lado, su nivel educativo no les permite prever el alcance real y la importancia de los derechos humanos, y esta confusión, existente entre la población desplazada, sobre lo que significan los derechos humanos, hace que simplemente se limiten a buscar intermediarios o no ejerzan sus derechos por temor al reproche.

Por otro lado, la mayor parte de esta población decide o desea, así, tener dinero para pagar y evitar los largos trámites y la enorme cantidad de diligencias, de ahí los innumerables casos de personas desplazadas solicitando colaboración en diferentes lugares.

Además de esto, la gran mayoría de los asistentes a los talleres de capacitación sólo conoce la tutela y el derecho de petición como mecanismos para restablecer y reivindicar sus derechos y, sin embargo, dicen que no son muy eficaces. La información que poseen sobre estos derechos les ha sido entregada por los demás compañeros.

Todos reciben atención del Estado y se encuentran más o menos satisfechos, y conocen pocos o casi ningún mecanismo jurídico diferente a la tutela y al derecho de petición. Sin embargo, no todos las han utilizado como opciones para resolver sus problemas y opinan que son buenas para recibir prontamente los dineros de los auxilios.

Por último, las comunidades están convencidas de que el Estado no las protege tanto como debería y están dispuestas a recibir capacitación en estos temas.

\section{Congestión en la presentación de peticiones ante la UARIV e incumpli- miento en los términos de respuesta}

Según la información suministrada por el Departamento Administrativo para la Prosperidad Social y la Unidad Administrativa para la Atención y Reparación Integral a las Víctimas (ver anexo 2), mensualmente se reciben 2.600 peticiones a nivel nacional, radicadas en la entidad por víctimas del conflicto armado interno, en las cuales solicitan la solución a diversos interrogantes que los aquejan, como son: los procedimientos a seguir para quedar inscritos en el $R U V$, las razones que motivaron la negativa a ser inscritos en el $R U V$, la división de su núcleo familiar, la entrega y prórroga de la atención humanitaria de emergencia y de transición, el procedimiento y los documentos necesarios para el pago de la reparación/indemnización administrativa, la expedición del acto administrativo mediante el cual se les reconozca y ordene pagar la reparación/indemnización administrativa, los requisitos y documentos necesarios para acceder a los proyectos de estabilización socioeconómica, y la expe- 
dición de certificados en los que conste que el peticionario y su familia son víctimas de desplazamiento forzado.

La efectividad de la $U A R I V$ para responder estas peticiones se puede resumir en el presente cuadro, en el cual se evidencia que de las 2.600 peticiones presentadas entre agosto y septiembre de 2014, se respondieron el 70 \% de ellas, de las cuales se accedió a lo pretendido en el $55 \%$ de los casos; por otro lado, la mayoría de los casos que fueron resueltos en forma negativa o que no se resolvieron tienen que ver con peticiones sobre el reconocimiento y pago de la indemnización por vía administrativa. De igual forma, de las respuestas otorgadas a los derechos de petición (70 \%), solo el $68 \%$ se resolvieron dentro del término legal de 15 días y las demás fueron resueltas de forma extemporánea.

\begin{tabular}{|l|c|}
\hline \multicolumn{1}{|c|}{ Tema de la Petición } & No. de peticiones \\
\hline Inscripción en el RUV y relacionados & 625 \\
\hline División del núcleo familiar & 210 \\
\hline $\begin{array}{l}\text { Entrega y prórroga de la atención humanitaria de emer- } \\
\text { gencia y de transición }\end{array}$ & 958 \\
\hline Procedimiento y pago de indemnización administrativa & 653 \\
\hline Proyectos de estabilización socioeconómica & 74 \\
\hline Expedición de certificados de víctimas & 70 \\
\hline Otros temas & 10 \\
\hline
\end{tabular}

Peticiones resueltas: 1820

Peticiones no resueltas: 780

Total: 2600

\section{La ausencia de garantías para el acceso a la justicia contribuye a la persis- tencia del estado de cosas inconstitucional con respecto a los derechos de las víctimas de desplazamiento forzado}

Como se anotó en la parte inicial del presente documento, la Corte Constitucional declaró en la sentencia T-025 de 2004, la existencia de un estado de cosas inconstitucional en la situación de la población desplazada debido a la falta de concordancia entre la gravedad de la afectación de los derechos reconocidos constitucionalmente y desarrollados por la ley, por un lado, y el volumen de recursos efectivamente destinados a asegurar el goce efectivo de tales derechos, así como la capacidad institucional para implementar los correspondientes mandatos constitucionales y legales, por otro lado. Entre las múltiples vulneraciones a los derechos de las personas desplazadas, destacadas por la Corte, se encuentra la negación del acceso a la justicia.

La declaratoria mencionada, tiene su explicación en la presencia de cinco factores que caracterizaban, en su momento, la situación de los derechos humanos de las personas desplazadas; y que eran, en su conjunto, la causa del fracaso de la política pública en materia de desplazamiento: 
i) Las graves violaciones a los derechos humanos de las personas desplazadas.

ii) El fenómeno frecuente y con tendencia al crecimiento del uso de la acción de tutela como único mecanismo efectivo de reclamación ante las diferentes entidades del Sistema de atención integral a la Población Desplazada, para la obtención de la asistencia establecidas por ley a favor de esta población, así como la integración de facto del mecanismo de la acción de tutela al procedimiento administrativo como requisito previo indispensable para recibir las ayudas.

iii) La condición de vulnerabilidad de las personas desplazadas y la vulneración masiva de sus derechos (agravada por la inexistencia de recursos suficientes para la adecuada atención de las necesidades prioritarias de dicha población), la exigencia de numerosos trámites administrativos que retrasaba el acceso de los desplazados a las ayudas requeridas, la deficiente coordinación entre las diferentes entidades del sistema, la omisión de las autoridades administrativas para plantear soluciones a los problemas conocidos y persistentes, y la deficiente formulación de la política pública de atención en sus instrumentos.

iv) La omisión por parte de las autoridades y, en ocasiones, la propia acción de dichas autoridades del nivel local, así como del nivel nacional, encargadas de la administración y disposición de los recursos, contribuye a la situación de vulneración de los derechos humanos de las personas desplazadas, puesto que no permite que los componentes de la política pública se han aplicados por igual a la población objetivo.

v) La falta de correspondencia entre las disposiciones normativas sobre atención a la población desplazada y la realidad de la atención que se brinda a dicha población, especialmente por la deficiente disposición de recursos para garantizar la ejecución de la política pública.

En la sentencia T-025 de 2004, la Corte reiteró el reconocimiento del derecho a la justicia. Por consiguiente, el seguimiento al cumplimiento de las órdenes de dicha sentencia, adelantado por la Corte Constitucional, ha incluido, entre otros derechos de las víctimas del desplazamiento, el derecho a la justicia. A través del auto 008 de 200948, la Corte Constitucional puso en evidencia una situación que vulnera de manera flagrante una garantía básica, que posibilita el goce del derecho, que tienen las víctimas de desplazamiento, a tener acceso a la justicia. Garantía soportada sobre la base de que la acción de tutela ha sido integrada por las autoridades administrativas, de tal forma que les permita a las personas en condición de desplazamiento acceder sin mayores dificultades a la ayuda y la exigibilidad de sus derechos.

Como se puede apreciar, los cinco grandes problemas que dieron lugar a la declaratoria de estado de cosas inconstitucional, persisten luego de transcurridos cinco años. La actitud de las instituciones, de igual forma, no ha variado y los trámites impuestos a las personas desplazadas, exceden el tiempo y los costos que una víctima de un delito puede asumir, dificultando la satisfacción de las necesidades más elementa- 
les de un ser humano que ha sido despojado de todo y cuyos derechos, son violentados también por el engranaje institucional que, por el contrario, debería orientarlos en el difícil camino de la exigencia de justicia, verdad y reparación.

\section{Los avances para garantizar el acceso de las personas desplazadas a la ad- ministración de justicia son escasos y lentos}

A continuación, se analiza el acceso de las víctimas del desplazamiento a la administración de justicia, pertinente para el seguimiento al estado del cumplimiento de las órdenes señaladas en los autos 008 de 2009 y 092 de 2008. Dicho análisis, está basado en la información obtenida por la Comisión Colombiana de Juristas, sobre la política pública, contrastada con las responsabilidades de las entidades del Sistema Nacional de Atención Integral a la Población Desplazada (SNAIPD), relativas a los derechos, a la verdad, la justicia, la reparación y a la no repetición.

Tal como advierte la Corte Constitucional en el auto 008, en el año 2000 se tipificó el delito de desplazamiento forzado en el Código de Procedimiento Penal. Desde entonces, son pocos los casos en los que la Fiscalía General de la Nación ha iniciado de oficio las respectivas investigaciones por dicho delito, lo que supone un grave incumplimiento de la obligación estatal de investigar, perseguir y sancionar, a los responsables de violaciones a los derechos humanos; al igual que la inaplicación de los Principios Internacionales sobre lucha contra la impunidad, que establecen que la iniciativa del enjuiciamiento de violaciones a los derechos humanos, es una responsabilidad del Estado.

La Fiscalía General de la Nación, ha reportado la adopción de medidas relacionadas con la acción de la justicia sobre el delito de desplazamiento forzado, que deben contrastarse con las órdenes emitidas por medio del auto 008 de 2009.

La Fiscalía General de la Nación no ha avanzado en las investigaciones por el delito de desplazamiento forzado. La Corte Constitucional ha emitido órdenes específicas dirigidas a solucionar las omisiones estatales en materia de investigación del delito de desplazamiento forzado, como lo evidencia este auto:

Con el fin de avanzar en la reducción de la impunidad frente al delito de desplazamiento forzado y asegurar un intercambio de información adecuado entre el RUPD y la Fiscalía en relación con este delito, se solicitará al Fiscal General de la Nación que diseñe, a más tardar el 4 de mayo de 2009, una estrategia que permita avanzar de manera autónoma en la investigación del delito de desplazamiento forzado sin que necesariamente dependa de la existencia de concurso con otras conductas delictivas. (Auto 008, 2009).

En agosto de 2009, la Fiscalía informó que se encuentra trabajando en:

[...] el diseño de metodologías investigativas diferenciales para estos casos al tratarse de un punible que viola de manera grave el Derecho internacional humani- 
tario, con el objetivo prioritario de orientar la acción de los operadores jurídicos hacia el incremento de la calidad de las investigaciones, la maximización de los recursos disponibles y el tratamiento digno a las víctimas. (Respuesta al Derecho de Petición DF 55/1 de 31 de agosto de 2009)

En esa dirección, la Fiscalía ha reportado, como su acción de cumplimiento de la anterior disposición, la elaboración del Memorando 035 de abril 28 de 2009, relativo a la formulación de una estrategia investigativa para el abordaje autónomo del delito de desplazamiento forzado. Sin embargo, en su respuesta al derecho de petición, presentado por la Comisión Colombiana de Juristas, la Fiscalía no adjuntó el mencionado Memorando, ni expuso el estado de implementación del mismo o los resultados alcanzados mediante dicha estrategia investigativa.

Lentos avances en el intercambio de información entre la Fiscalía y el Registro Único de Víctimas. En materia de manejo de la información, también ha sido lenta la actuación de la Fiscalía. En relación con la orden del auto 008, acerca de la creación un mecanismo de intercambio de información con el $R U V$, en agosto de 2009 la Fiscalía informó que se conformó una Mesa especial para el diseño e implementación del mecanismo de intercambio fluido y seguro de información entre las bases de información de la Fiscalía General de la Nación y el $R U V$, a cargo de Acción Social, con el fin de identificar a la población víctima de desplazamiento forzado cuyos casos no hayan sido judicializados. No obstante, transcurridos ocho meses desde la expedición del auto 008, la Fiscalía no ha dado cuenta de las actividades desarrolladas por dicha Mesa, como tampoco de su plan de actividades y cronograma, lo que genera preocupación por la ausencia de avances en el intercambio de información.

Un escaso porcentaje de los procesos penales por el delito de desplazamiento forzado concluyen en sentencia. Hasta septiembre 17 de 2009, la Fiscalía General de la Nación, informó a la Comisión Colombiana de Juristas sobre la etapa procesal penal de los casos activos que lleva por el delito de desplazamiento forzado.

En el marco de la ley 906 de 2004, de los 5.536 casos activos, el 99,87 \% (5.529 casos) aún no cuenta ni siquiera con individualización del (de los) autor (es) ya que se encuentran en la etapa de indagación, sólo el 0,01 \% (1 caso) están en etapa de investigación, el 0,09 \% (5 casos) están en etapa de juicio y el 0,01% (1 caso) se terminó anticipadamente.

La información suministrada por la Fiscalía no da cuenta del total de casos inactivos, ya sea por preclusión, por haber sido archivados o por haberse proferido algún tipo de sentencia tanto absolutoria o condenatoria.

En el marco de la ley 600 de 2000, de los 2.649 casos activos, el 96,68 \% (2.561 casos) no cuenta siquiera con la identificación del (de los) presunto (os) autor (es), pues se encuentra en etapa de investigación preliminar y apenas el 3,32 \% (88 casos) se encuentra en etapa de instrucción. 
En uno u otro marco legal, se observa que el porcentaje de impunidad sobre las etapas del proceso penal, en los casos activos que reporta, sigue siendo casi del 100 $\%$; es decir, casi la totalidad de estos casos aún está lejos de tener una sentencia condenatoria.

La rama judicial no dispone de información integrada y coherente acerca de los procesos penales por el delito de desplazamiento. En el período comprendido entre enero y junio de 2009, el Consejo Superior de la Judicatura, contaba con 41 registros por procesos relacionados con desplazamiento forzado que aparecen en el Sistema de Información Estadística de la Rama Judicial (SIERJU). Sin embargo, el balance de dicha información es de 13 sentencias, en las cuales se condenó a nueve personas y fueron absueltas tres.

Es necesario subrayar que el bajísimo volumen de sentencias condenatorias por el delito de desplazamiento forzado, contrasta radicalmente con la creciente magnitud del desplazamiento, estimada en 4 millones de víctimas de este delito.

Además, el Consejo Superior de la Judicatura, afirma que se requiere trabajo de campo para ofrecer información sobre sentencias en las cuales se haya ordenado la restitución de tierras y bienes de las personas desplazadas, así como el tipo y cantidad de medidas cautelares (en caso de haber sido ordenadas) sobre los bienes entregados en el marco de la ley 975 de 2005, e información más detallada sobre los procesos en los que se haya dictado sentencia condenatoria:

Con relación a la solicitud de variables de profundización como: número de radicado, nombre de las víctimas, lugar y fecha de los hechos nombre de las personas a quienes se les dictó medidas de aseguramiento, etc., así como las contempladas en el numeral 4, es importante señalar que corresponden a variables de profundización, las cuales requieren de un trabajo de campo para su obtención.

La disponibilidad de información actualizada y consolidada sobre procesos penales, que están siendo tramitados en los diferentes despachos judiciales de todo el país, es muy importante para las funciones de todas las entidades de la Rama Judicial, y para monitorear el desempeño de la justicia y la evolución de los procesos penales que se adelantan por el delito de desplazamiento forzado, sin que sea necesario desplegar un trabajo de campo para obtener la información solicitada mediante derecho de petición o por la misma Corte Constitucional.

No existen garantías para acceder al sistema judicial mediante un recurso efectivo. La interposición de múltiples trabas de tipo administrativo y presupuestal, en el camino hacia la reclamación de justicia y verdad para las víctimas del desplazamiento, se constituye como una denegación de justicia y lleva a las víctimas a la pérdida de confianza en el sistema judicial.

A largo plazo, la falta de protección de los derechos de las víctimas durante el desplazamiento, agrava su situación de vulnerabilidad y posibilita la comisión de 
violaciones adicionales a los derechos de las víctimas, relacionadas, entre otros, con fenómenos como la violencia intrafamiliar, el trabajo infantil, la violencia sexual por razones de género, la explotación laboral, las amenazas, los homicidios, el reclutamiento forzado y la repetición del desplazamiento forzado.

En los distintos componentes y fases de las peticiones de personas desplazadas persisten muchos de los obstáculos que demoran o impiden la atención. Como se ha mencionado en el presente informe, la lentitud o la negativa de asistencia por parte de muchas entidades del SNAIPD, conduce a las víctimas a acudir frecuentemente a la vía de la acción de tutela como mecanismo de protección de sus derechos. Según la Corte Constitucional, cada mes se radican aproximadamente 400 tutelas en las cuales el accionante es una persona desplazada.

Como ha advertido la Corte Constitucional, el elevado volumen de acciones de tutela es uno de los elementos constitutivos del "estado de cosas inconstitucional" declarado a través de la sentencia T-025 de 2004.

El acceso formal al sistema judicial no garantiza a las víctimas la obtención de una decisión de fondo sobre el delito de desplazamiento forzado. Las cifras citadas en el presente reporte, evidencian que, a pesar de la masividad del delito de desplazamiento, un bajo porcentaje de casos por ese delito son investigados. Tal como afirma la Fiscalía, hasta septiembre de 2009 se conocían 8185 casos, de los cuales solamente cinco se encontraban en etapa de juicio.

La información disponible muestra un desempeño muy deficiente de la justicia en relación con el delito de desplazamiento forzado, lo cual contrasta con la jurisprudencia de la Corte Constitucional acerca del derecho de acceso a la justicia, cuyo contenido sustancial radica "sobre todo en la posibilidad real y verdadera, garantizada por el Estado, de que quien espera resolución - ya por la vía activa, ora por la pasiva- la obtenga oportunamente" (Sentencia T-190, 1995).

Asimismo, la expectativa de las víctimas que acuden a la administración de justicia es obtener una decisión judicial que sancione a los responsables del delito. Si no se obtiene dicha decisión, se deteriora la confianza en el Estado y se desestimula la demanda de justicia.

Ahora bien, en su Informe de Gestión 2008-2009, la Fiscalía General de la Nación indicó que para abril de 2009 existían 178 casos asignados a la Unidad Nacional de derechos humanos y al derecho internacional humanitario, de los cuales el 74,71 \% (133 casos) no cuenta con identificación del (os) presunto (s) autor (es), ya que se encuentran en etapa de indagación (128 casos en ley 906) o investigación preliminar ( 5 casos en ley 600). Por otro lado, el 2,86 \% (5 casos) fueron declarados inhibitorios, el 7,3\% (13 casos) se encuentran en etapa de instrucción con imputado conocido, el $7,3 \%$ (13 casos) están etapa de juicio y el 6,17 \% (11 casos) ya cuentan con sentencia condenatoria. En tres casos se desconoce la etapa del proceso. 


\section{Las víctimas de desplazamiento forzado han tenido que acudir a la acción de tutela para la protección de sus derechos}

A continuación se analizarán los datos recogidos en los Juzgados Administrativos Orales de Bogotá, sobre el número de tutelas radicadas contra la UARIV, los temas de las tutelas, la defensa que ejerce la $U A R I V$ en el curso de estas acciones constitucionales y, sobre la efectividad en el cumplimiento de los fallos de tutela.

En el transcurso del 2014, los Juzgados Administrativos Orales de Bogotá han recibido en promedio 150 tutelas por despacho, de las cuales 90 son contra la UARIV (ver anexos 2 y 3). Para esta investigación se tomó como muestra el Juzgado Tercero Administrativo Oral de Bogotá, el cual ha recibido, en el transcurso del año 2014, 156 acciones de tutela, de las cuales 106 han sido contra la UARIV.

De las 106 tutelas radicadas contra la $U A R I V$, se estableció que en el $79.5 \%$ de los casos (75 tutelas) se accedió a las pretensiones de la demanda, mientras que en el 29.5 \% se negó el amparo de los derechos fundamentales invocados.

Entre los derechos fundamentales que los accionantes invocan en las acciones de tutela como vulnerados, se encuentran predominantemente los de petición, igualdad, mínimo vital y los derechos de las víctimas.

La mayor parte de acciones de tutela se interpusieron porque, dentro del término legal de 15 días, la $U A R I V$ no respondió las peticiones formuladas por las víctimas de desplazamiento forzado. De los 106 casos analizados, en total se encontraron 84 acciones invocando la protección del derecho de petición, lo cual corresponde al 89.04 $\%$; el porcentaje restante corresponde a temas como reconocimiento y pago de la indemnización administrativa (15.9\%) y a reclamos por inconsistencias en la inclusión en el RUV (7.42\%). 


\section{REFERENCIAS BIBLIOGRÁFICAS}

\section{Libros y artículos}

Ariza, L. J. (2009). Derecho, saber e identidad indígena. Bogotá: Universidad de los Andes, Siglo del Hombre.

Bohada, M. d. P. (2010). Desplazamiento forzado y condiciones de vida de las comuni-dades de destino: el caso de Pasto, Nariño. Revista de Economía Institucional, 12(23), 259-298.

Gómez, F. (2014). El desplazamiento forzado de los pueblos indígenas en Colombia. Anuario español de derecho internacional, (30), 431-455.

Fundación Hemera. (2006). Diagnóstico de grupos indígenas en Bogotá y lineamientos de política pública para la atención de grupos étnicos.

Mora-Gamez, Fredy A. (2013). Reconocer a los reclamantes: sobre el Registro Único de Víctimas en Colombia como ensamble socio-técnico. IM-Pertinente, 1 (1), 11-32.

Villa, W. y Houghton, J. (2005). Violencia política contra los pueblos indígenas en Colombia: 1974-2004. Bogotá: Cecoin y oia.

\section{Reportes y entrevistas}

Ancur. (2009). Perder nuestra tierra es perdernos nosotros. Los indígenas y el desplazamiento forzoso en Colombia. Recuperado de: http://www.acnur.org/t3/fileadmin/ Documentos/RefugiadosAmericas/Colombia/Los_indigenas_y_el_desplazamiento_forzoso_en_Colombia.pdf?view=1

Alto Comisionado de las Naciones Unidas para los Refugiados. (2012). Situación Colombia: pueblos indígenas. Recuperado de: http://www.acnur.org/t3/fileadmin/Documentos/RefugiadosAmericas/Colombia/2012/Situacion_Colombia_-_Pueblos_indigenas_2012.pdf?view=1.

Bodnar, Yolanda. (2005). Pueblos Indígenas de Colombia: Apuntes Sobre La Diversidad Cultural y La Información Sociodemográfica Disponible. En: Notas de Población, No. 79, CEPAL/CELADE División de Población, Santiago de Chile. ISBN92-1322776-0, ISSN Impreso 0303-1829, p.p. 231-262.

Contraloría General de la República. (2013). Evaluación del proceso de indemnización administrativa a las víctimas de la violencia en Colombia -año fiscal 2012-. (2013). (Radicado n. ${ }^{\circ}$ 2012EE0067851) Recuperado de: http://www.contraloria.gov. co/documents/155638087/161616402/Informe+Indemnizaci\%C3\%B3n+Administr ativa.pdf/f3972d84-3451-44da-829a-240b79fc5c10?version=1.0.

Hoy las víctimas existen para el país: Paula Gaviria. (Septiembre, 2013). El nuevo siglo. co. Recuperado de: http://www.elnuevosiglo.com.co/articulos/9-2013-hoy-lasv\%C3\%ADctimas-existen-para-el-pa\%C3\%ADs-paula-gaviria.html.

Unidad para la Atención y Reparación Integral a las Víctimas. (2013). Informe Nacional de Desplazamiento Forzado en Colombia 1985-2012. Recuperado de: http:// 
www.cjyiracastro.org.co/attachments/article/500/Informe\%20de\%20Desplazamiento\%201985-2012\%20092013.pdf.

Unidad para la Atención y Reparación Integral a las Víctimas. (2012). Informe de gestión. Recuperado de: http://www.accionsocial. gov.co/ documentos /7514_Informe_de_ Gesti\%C3\%B3n_Unidad_V\%C3\%ADctimas_-_dic31_31ene.pdf.

\section{Leyes y decretos}

Constitución Política (1991).

Congreso de la República de Colombia. Ley 160 (1994).

Congreso de la República de Colombia.. Ley 387 (1997).

Congreso de la República de Colombia.. Ley 1437 (2011).

Congreso de la República de Colombia.. Ley 1448 (2011).

Presidencia de la República de Colombia. Decreto 2591 (1991).

Presidencia de la República de Colombia.. Decreto 2569 (2000).

Presidencia de la República de Colombia.. Decreto 1290 (2008).

Presidencia de la República de Colombia. Decreto 4800 (2011).

Presidencia de la República de Colombia.. Decreto 1377 (2014).

Presidencia de la República de Colombia.. Decreto Reglamentario número 2164 (1995).

Organización Internacional del Trabajo. Convenio 107 (1957).

Organización Internacional del Trabajo.. Convenio 169 (1989).

\section{Jurisprudencia}

Corte Constitucional de Colombia. Sentencia T-025 (2004). M. P. Manuel José Cepeda.

Corte Constitucional de Colombia. . Sentencia T- 496 (2007). M. P. Jaime Córdoba Triviño.

Corte Constitucional de Colombia. . Sentencia T-039 (2009). M. P. Rodrigo Escobar Gil. Corte Constitucional de Colombia. -. Auto 004 (2009). M. P. Manuel José Cepeda.

Corte Constitucional de Colombia. . Sentencia T-282 (2011). M. P. Luis Ernesto Vargas.

Corte Constitucional de Colombia. . Sentencia T-402 (2011). M. P. Gabriel Eduardo Mendoza.

Corte Constitucional de Colombia. . Sentencia T- 370 (2013), M. P. Jorge Iván Palacio.

Corte Constitucional de Colombia. -. Sentencia SU-254 (2013), M. P. Luis Ernesto Vargas Silva. 

Esta obra se editó en Ediciones USTA, Departamento Editorial de la Universidad Santo Tomás. Se usó papel esmaltado de 300 gramos para la carátula y papel bond beige de 70 gramos para páginas internas. Tipografía: Minion Pro. Impreso por Digiprint Editores S.A.S. 
El problema del desplazamiento forzado, en el marco del actual conflicto que vive Colombia, ha permeado a todas las realidades y personas, desestabilizando el orden y equilibrio de las comunidades que integran el tejido social del país. Este hecho lamentable perjudica a todos los colombianos sin distinción de género, raza, grupo cultural o credo, pero ha recaído especialmente sobre los grupos humanos más vulnerables por sus condiciones territoriales y socioeconómicas: afrodescendientes, campesinos e indígenas.

El presente libro es el resultado de un proceso realizado con las comunidades indígenas Inga y Tukano, asentadas en Villavicencio. Evalúa, en materia jurídica, la eficacia de los mecanismos de protección y los programas de reparación integral diseñados para las comunidades indígenas víctimas de desplazamiento forzado, y promueve tanto la difusión y conocimiento, como la práctica y reformulación, de los mecanismos jurídicos de protección en materia de derechos humanos para que estas comunidades víctimas no solo hagan frente y respondan desde su propia voz, sino que además transformen y se transformen en actores participativos de una realidad social y política que debe mejorar desde unas prácticas políticas y jurídicas más inclusivas y sensibles. 